\title{
ENSAIOS
}

\section{A escrita de si, práticas discursivas socioculturais e ficção no desejo homoerótico feminino em Cassandra Rios}

\section{Rubenilson Pereira de Araujo ${ }^{1}$}

"Se o homem escreve, ele é sábio, experiente. Se a mulher escreve, é ninfomaníaca, tarada" (Cassandra Rios).

Pelas mãos e pelo desassombro de pessoas que perceberam na poesia aquela sutil e isteriosa habilidade para resistir à brutalidade dos tiranos. E acender, ainda tênue, um lume de esperança no coração dos que lutam" (Pedro Tierra $)^{2}$.

As epígrafes deste texto remontam ao ato da escritura como uma ação de resistência à opressão institucionalmente imposta, a poesia soa como uma forma de grito pela liberdade e visibilidade abafados pela opressão. Nesse sentido, o cerne dessa breve escrita é um olhar/leitura para Cassandra Rios, a qual impõe uma autoria feminina, através de seus personagens, busca expor a invisibilidade, a condição de objeto da mulher e, acima de tudo, a perseguição e falta da legitimação do desejo lésbico como algo possível na eroticidade do desejo humano. No excerto da obra intitulada Maria Padilha, a autora afirma o seguinte:

(...) Desde o início da minha carreira, eu venho sendo perseguida por ter descerrado a cortina da hipocrisia, por ter rompido preconceitos e por ter desprezado e pisado em tabus a fim de despertar interesse por determinado assunto, libertando-o das amarras da falsa moral e do puritanismo (...) Joguei com a coragem, sem medo dos escândalos, sem temer as falsas interpretações e o meu envolvimento pessoal e sem me acovardar diante das perseguições (RIOS, 1979, p. 8).

Mediante a ousadia da autora, poderíamos afirmar que, intencionalmente, ela remete no título da obra supracitada ao nome de uma entidade feminina emblemática das religiões de matrizes africanas, uma das figuras de pomba-gira míticas mais famosas

\footnotetext{
1 Doutor em Letras: Ensino de Língua e Literatura pelo PPGL da Universidade Federal do Tocantins/UFT, onde atua na graduação e pós-graduação em Letras, campus P. Nacional desenvolvendo pesquisas sobre gênero, diversidade sexual, educação linguística e literária na Formação Inicial e Continuada de Professores da Educação Básica. E-mail: rubenilsonaraujo@uft.edu.br

${ }^{2}$ TIERRA, 2010, p. 18.
} 
nos terreiros afro-brasileiros. Maria Padilha é uma pombo-gira que representa a imagem de um Exu feminino,

[n]o imaginário afro-brasileiro, pomba-gira é um Exu, um Exu do sexo feminino, um Exu-mulher ou, para alguns, um Exu-fêmea ou "Exua" (termo tão difundido na literatura acadêmica). Como todo Exu, Pomba-gira representa a sublevação, a transgressão ostensiva de normas e condutas de uma moralidade conservadora. Pomba-gira é rebelião, litígio, demanda. É também sedução, sensualidade, coragem, inquietude, alegria, arrogância, ardor (BARROS, 2006, p. 62).

Mediante tais cargas semânticas de adoção da amostragem de um dos títulos intencionais das obras de autoria de Cassandra Rios, afirmamos que, antes de tudo, é imprescindível ressaltar que o lugar de fala assumido nesta breve escritura não é neutro, está longe da cientificidade higienista cartesiana e procura posicionar-se com uma postura transgressora de gênero que resiste à opressão, muitas vezes, institucionalmente imposta em meio aos olhares, sanções e punições inquisidoras da sociedade vigente.

Nos paradigmas emergentes de ciência está em voga atualmente a fala e/ou a escrita de si, sobretudo no tocante às narrativas escritas ou oralizadas que o crivo do cânone estabelece como legítimas ou oficializadas. Nesse sentido, corroboramos com o discurso emblemático de Chimamanda Adichie em "O perigo de uma única história", 2012, s/p, em que ela afirma que "Histórias têm sido usadas para expropriar e tornar maligno. Mas podem também ser usadas para capacitar e humanizar. Histórias podem destruir a dignidade de um povo, mas também podem reparar essa dignidade perdida”.

Nesse sentido de que as verdades podem emergir mediante as histórias que contam, sejam elas ficção ou realidade que se mesclam, é importante buscar a contação de histórias (orais e escritas) para fins de humanização, resgatando muitas vezes dignidades de pessoas ou grupos, perdidas em meio às hegemonias socioculturalmente impostas. Há, portanto,

[...] a necessidade de conceber a vida como este eterno gerúndio em que receitas culturais prontas, acabadas e impostas precisam ser contestadas, desfeitas e reconstruídas pelo prisma de sujeitos que emergem das zonas sombrias que nos lançaram ao longo do caminho da História, tornando-nos incapazes de visualizar nossas próprias sombras. À medida que coexistimos como sujeitos cognoscentes, participando de um mundo comum, tornamo-nos seres mais iluminados (ARAUJO, 2018, p. 37).

Este lugar isento de neutralidade e transgressor de gênero parte de dados que algumas pesquisas e movimentos sociais demonstram recentemente sobre a realidade 
altamente misógina e que se intersecciona com diversos outros fatores de raça, classe e outros indicadores socioculturais em nosso país, como:

- Duas, em cada três vítimas de feminicídio foram mortas dentro da própria casa, segundo pesquisa feita pelo Núcleo de Gênero do Ministério Público de São Paulo, publicada em março de 2018. Estimam-se ainda no país que cinco mulheres são espancadas a cada 2 minutos. Em mais de $80 \%$ dos casos, o agressor é um parceiro ${ }^{3}$.

- Nas prefeituras dos municípios brasileiros, apenas 3,29\% de mulheres negras assumem o cargo de chefia do poder público executivo, segundo o Mapa Étnico Racial das Mulheres na Política Local Brasileira, divulgado em julho de 2018. Dados do observatório de gênero demonstram ainda que em relação à presença de mulheres no parlamento, nosso país está posicionado em $154^{\circ}$ lugar, considerando $10,7 \%$ de mulheres na Câmara e $14,8 \%$ no Senado.

- $\quad$ No ano de 2015, um estupro foi registrado a cada 11 minutos, segundo o Anuário Brasileiro de Segurança Pública.

O quadro demonstrado acima se agrava ainda mais quando se parte para as questões de gênero e diversidade sexual, no tocante às lésbicas, gays, bissexuais e, sobretudo, travestis e transexuais. È notório observar que vivemos em um país marcado por crimes de ódio, homofobia e transfobia, um verdadeiro genocídio de pessoas dissidentes da heteronormatividade e cisgeneridade. Segundo o relatório do Grupo Gay da Bahia/GGB ${ }^{4}$, organização não governamental que realiza a catalogação dos crimes homofóbicos no país e age em defesa dos direitos humanos das pessoas LGBT, desde 1980, notificou que no ano de 2016, por exemplo, foram registrados 343 assassinatos de gays, lésbicas, bissexuais e transgêneros em todas as regiões geográficas do país.

Mediante este quadro alarmante no tocante às questões de gênero e, sobretudo em relação à diversidade sexual, podemos vislumbrar as malhas da ficção como uma possibilidade de desenvolver a questão da alteridade, um olhar para o outro, que mesmo imerso em seus dilemas, ainda permanece inalteradamente humano, visto que a literatura transfigura a realidade em palavras. Trata-se, segundo Antonio Candido, de um direito humano no que concerne à representação ou auto representação da

\footnotetext{
${ }^{3}$ Pesquisa: Mulheres Brasileiras nos Espaços Público e Privado (Fundação Perseu Abramo/Sesc, 2010.

${ }^{4}$ Fonte: https://homofobiamata.files.wordpress.com/2017/01/relatc3b3rio-2016-ps.pdf Acesso em 11 de setembro de 2017.
} 
humanidade em si, negar esse gozo estético ao sujeito é solapar um direito existencial. A leitura do texto literário corresponde a

\begin{abstract}
Uma necessidade universal que deve ser satisfeita sob pena de mutilar a personalidade, porque pelo fato de dar forma aos sentimentos e à visão do mundo, ela nos organiza, liberta do caos e, portanto, nos humaniza. Negar a fruição da literatura é mutilar nossa humanidade (CANDIDO, 2004, p. 186).
\end{abstract}

Em outras palavras, podemos corroborar que a Literatura e outras artes, de modo geral, refinam o olhar do humano para possíveis situações de barbáries socioculturais. A D. Literatura, portanto, auxilia no equilíbrio, pois, "assim como não é possível haver equilíbrio psíquico sem o sonho durante o sono, talvez não haja equilibro social sem a Russianketem destuoss concepção de uma Literatura "verdadeiramente viva, [...] humana e subversiva o suficiente para dialogar com as contradições e paradoxos da vida real, (d)enunciando mazelas, exaltando o gozo estético e apontando tomadas de decisões" enunciativas dos sujeitos (ARAUJO, 2018, p. 245).

Sendo assim, o recorte neste texto, volta-se para uma escritura de autoria feminina em uma época notadamente marcada e denominada como "os anos de chumbo" (1964 - 1985), em que registramos na história as marcas indeléveis da Ditadura Militar, na qual foi instituído o Ato Institucional número 5 (AI-5) que objetivou investigar, perseguir, punir e aniquilar qualquer oposição ao governo. As ações explícitas do biopoder agindo sobre a produção cultural e, sobretudo, vigiando e punindo os corpos que não seguiam os padrões impostos pela pseudo moral cristã e bons costumes eurocentrados, brancos, masculinos, cisgêneros, heterossexistas e classistas.

Neste contexto hostil, é mister afirmar o movimento e ação de vanguarda empreendidos por inúmeros personas reais na história oficial que portaram-se como verdadeiros mártires que dedicaram seus corpos como holocausto para uma emancipação de sujeitos e possibilidade de instalação da tão necessária democracia. Na verdade, a luta empreendida foi em prol da vez e voz daqueles que ainda sofrem nas sombras e porões da invisibilidade sociocultural, o que nos remete ao célebre discurso de uma pioneira do movimento feminista mundial: "venho até vocês hoje arriscando 
uma 'condenação penosa', como uma pessoa que somente tem paradoxos a oferecer e não problemas fáceis de serem resolvidos $5 \%$.

Historicamente, o golpe militar de 1 de abril de 1964 faz com que o país negue veementemente a Constituição de 1946, destituindo o Estado de Direito, o que faz a população passe a viver em uma nação que se legitimava pela força dos canhões.

Nesse contexto, é importante ressaltar que a classe de quem primeiro se manifesta resistindo a esta opressão mutiladora são os artistas que passam a produzir manifestações artísticas de denúncias e engajadas socioculturalmente como forma de D repudiar a situação desumanizadora institucionalmente instalada.

1. Corroboramos nesse recorte representativo aqui pela escritora Cassandra Rios, pois o contexto em que ela viveu inserida, a arte e a escrita tiveram importantes papeis

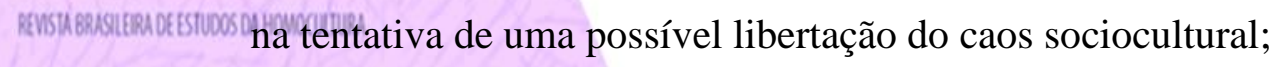

Em 21 anos de ditadura foram tantos os mortos, os torturados e humilhados que faltaria espaço onde refugiar toda a sua dor. A memória, terreno tão propício, é demasiadamente instável para semelhantes horrores. Talvez por isso os homens tenham inventado a arte. Picasso abrigou o grito de pavor de uma cidade espanhola em sua Guernica, os anos se passaram, mas o grito continua lá, ecoando diante de nossos olhos. No Brasil, foram os escritores que entalharam esse espaço acolhedor (DELCASTAGÈ, 1996, p. 15).

Metaforicamente com o introito do sangue de tantos mártires vanguardistas do passado e da contemporaneidade em prol da mudança sistêmica da produção das verdades em relação ao gênero e sexualidades plurais, reinfatizamos que o nosso olhar se volta nesse texto para uma literatura engajada da escritora Cassandra Rios (19322002) na (auto)representação de grupos de pessoas relegadas ao ostracismo sociocultural (homossexuais, como travestis, lésbicas cisgêneras e transgêneras, prostitutas, entre outros sujeitos representantes das minorias sexuais). Esta escritura pode ser adjetivada como homoerótica feminina, tal escrita traz em seu bojo a marca de opressão e resistência. Tal representação artística pode ser classificada como "fissuras socioculturais" que se manifestam onde predomina as relações assimétricas de poder, afinal, como afirma Michel Foucault, “onde há poder, há resistência” (FOUCAULT, 1988, p. 105).

\footnotetext{
${ }^{5}$ Autoria de Olympe de Gouges, pseudônimo de Marie Gouze (1748-1793) escreveu a Declaração dos direitos das mulheres e da cidadã (1791). Ela foi condenada à morte na guilhotina com a seguinte sentença: Olympe de Gouges nasceu com uma imaginação exaltada, confundindo seu delírio com uma inspiração da natureza. Ela queria ser um homem de Estado. Ela aderiu aos projetos do povo pérfido que queria dividir a França. Parece que a lei puniu esta conspiradora por ter esquecido as virtudes próprias do seu sexo".
} 
Escrever ou ler sobre Cassandra Rios é como projetar um mergulho denso em uma das mais notáveis escritoras brasileiras de nossa literatura do século XX. Ela intersecciona em sua escrita um misto significativo de questões de mitologia grega, traços de religiões de matriz africana e inaugura a (auto)representação do desejo homoerótico feminino invisibilizado e interseccionado com questões de raça, credo, classe e outros indicadores socioculturais.

Cassandra é um pseudônimo de Odete Rios (São Paulo, 1932 - São Paulo, 8 de março de 2002), o nome fictício é inspirado na mitologia grega que denota uma bela e D 10 sensual jovem que recebe o dom de profecia do deus Apolo, devido despertar-lhe a paixão. Devido a não correspondência às insinuações do deus grego, ela é amaldiçoada no exercício de seu dom profético. O complexo de Cassandra passa a ser uma sina de que, embora clarividencie a verdade, a pessoa não é legitimada socialmente e passa a sofrer a sina de mentirosa ou indigna de confiança e legitimação.

Para compreender Cassandra, é imprescindível entender o contexto da época. A sua obra emerge a estreita relação entre Literatura, História e memória - ponto de pauta de inúmeras discussões na contemporaneidade no âmbito da Literatura Comparada e dos Estudos Culturais.

Perrone-Moisés (1990) destaca que "a literatura parte de um real que pretende dizer, falha sempre ao dizê-lo, mas ao falhar diz outra coisa, desvenda um mundo mais real do que aquele que pretendia dizer" (PERRONE-MOISÉS, 1990, p.102). Quanto a isso, Corrêa comenta que a literatura "des-vela" o mundo: "Ora completa, harmonizando as lacunas do real e compensa o que falta para tornar a realidade satisfatória; Ora expõe cruamente, dolorosamente, as terríveis fissuras da realidade" (CORRÊA, 2009, p. 8).

Neste contexto de engajamento autoral com o tempo no qual se insere, Cassandra Rios assume a predestinação de seu pseudônimo em seu ofício de escritora e pode-se afirmar que ela escreveu para um destinatário, o qual era o seu próprio algoz: a censura. Em uma de suas obras, caracterizada como uma autobiografia, ela afirma: “escrever é vocação, é via crucis" (RIOS, 1977, p.116). Neste sentido, é possível depreender que a ela tinha nítida consciência que sua escrita era revolucionária para o seu tempo e que exigia o flagelo de seu corpo, enquanto objeto de vivência do exercício de cidadania, representado em sua própria produção. Na mesma obra, ela chega a assumir, metaforicamente, o papel do escritor compromissado com o público-objeto de sua arte: 
A responsabilidade do artista é mais séria, perigosa e delicada, pois sua mente é como um pássaro liberto que aspira a amplitude e os píncaros do infinito. O pássaro sabe que a distância o livra das chamas do sol, mas se esquece que alguém está sempre com uma tesoura aberta para cortar-lhe as asas, com uma arapuca armada para levá-lo para uma gaiola, porque entre os outros pássaros, sua plumagem, seu gorjeio, sua exuberância ou sua natureza grotesca o destacaram para a cobiça que traz intrínseca a inveja (RIOS, 1977, p.9-10).

Neste excerto, Cassandra menciona as tesouras do biopoder que se encontram sempre abertas para podar as asas da imaginação que a levaria a amplitude e píncaros do infinito de sua arte, além da inveja, cobiça devido a especificidade do objeto de 10 envergadura de sua escrita. Nessa perspectiva, é importante destacar a incógnita da N Titeratura de cunho homoerótico, que a crítica a rotula de mal vista, entretanto, trata-se desde a época retratada por Rios como muito consumida.

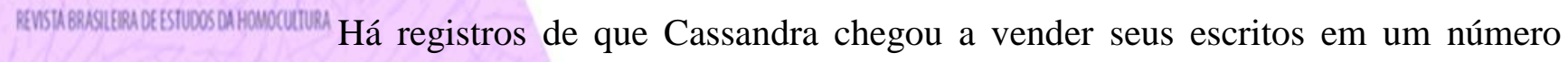
superior a trezentos mil exemplares por ano em plenos anos de chumbo da ditadura militar, uma literatura de autoria feminina não atingira tal recorde de vendas no Brasil. Tal fato ocorre, coincidentemente, também com a literatura pornográfica atual, envolvendo artefatos de cunho transex, o Brasil registra um dos maiores públicos que o acessa na rede mundial de computadores em contradição com o país que mais violenta de maneira letal a população do universo transgênero.

Nota-se, concomitantemente, verdadeira fascinação e repulsa em relação a esta população em que parece predominar uma tentativa de assepsia porque na maioria dos casos de assassinatos de travestis e transexuais, o assassino não se contenta com apenas um golpe letal, é como se quisesse matar mais de uma vez aquele corpo que transgrediu as normas de gênero e negou o falo que veio em sua morfologia biológica.

Ainda em relação à sociedade falocêntrica, é importante pensar que o ódio e aversão que se acentuam sobre as lésbicas é notadamente devido à negação do desejo pelo falo e, consequentemente, os nomes pejorativos que se lançam e os crimes mais virulentos de ódio recaem justamente sobre aqueles cujos corpos são biologicamente masculinos e se travestem, assemelhando-se ao corpo feminino. Daí, a ousadia de concordar que a homotranslesbofobia é altamente misógina, ou seja, o cerne do ódio da sociedade machista bélica é contra a performance de gênero feminina.

Cassandra Rios assume a autoria de uma literatura que representa o público feminino e seu desejo dissidente da heteronormatividade compulsória. Ela representa uma homossexualidade descolada da visão patológica ou psiquicamente desiquilibrada, em suas narrativas, notamos a construção de seres humanos que assumem seus desejos 
não padronizados por paradigmas tradicionais determinados pela biologia e se encontram marcados pela força da margem da exclusão social devido suas identidades de gênero ou orientação sexual.

Nos romances de Rios protagonizam seres humanos de carne e osso não idealizados, em sua primeira obra intitulada Volúpia do Pecado, publicada em 1948, quando a autora contava com apenas 16 anos de idade, ela retrata um caso homoafetivo e homoerótico entre duas personagens femininas com bastante naturalidade, sem patologizar ou criminalizar, e dando um desfecho positivo para a trama. Tal ineditismo D a coloca como a pioneira na Literatura homoerótica feminina, destacando-se também no cenário mundial.

A obra de Cassandra Rios é caracterizada por uma linguagem acessível ao

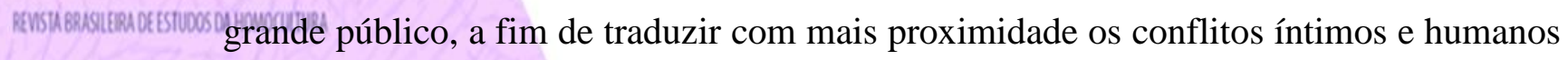
que muitos vivenciam, principalmente no tocante à questão de orientação sexual e identidade de gênero.

Sua ficção é inédita no que concerne ao mesclar o erótico e o pornográfico em uma época que, segundo Michel Foucault, o sexo transformou-se em discurso em virtude da força moralista cristã associada ao biopoder repressivo do Estado sob o regime militarista. Em relação à vivência da sexualidade, segundo o filósofo, era preciso examinar, vigiar, confessar, transformar em discurso, Foucault complementa que "poder falar da sexualidade se podia muito bem e muito, mas somente para proibí-la" (FOUCAULT, 1988, p. 9).

No tocante às artes, é importante diferenciar as linhas diferenciais tênues e sutis entre o pornográfico e o erótico. Partindo dos pressupostos teóricos de Dominique Maingueneau (2010) “o erotismo é, então, percebido de maneira ambivalente: às vezes como pornografia envergonhada, que não tem coragem de dizer seu nome” (p. 31). Sendo assim, notamos marcas do erotismo que se na obra de Cassandra, mas, também, notamos a abordagem da sexualidade humana, em que a pornografia canônica "se opõe frontalmente aos valores sociais dominantes: ela pretende ser apenas um discurso permissivo, que se desdobra em um universo sem culpabilidade" (MAINGUENEAU, 2010, p. 42). Nesse sentido, notamos o livre trânsito das ações dos personagens cassandrinos no desenvolvimento de suas narrativas e podemos afirmar que sua obra mescla características eróticas e pornográficas.

Provavelmente, a classificação da obra de Cassandra como meramente pornográfica se dá devido a visão reducionista do imaginário comum que ainda atrela a 
homossexualidade às práticas transgressivas do ato sexual, contrariando a visão cristã reducionista de que o sexo deve ter fins apenas para a procriação da espécie. Nas inúmeras tentativas de legitimação de sua obra, Cassandra chegou a escrever assinando com pseudônimos masculinos e narrando cenas de sexo explícitos heterossexuais e conseguiu êxito nas vendas e a obra não foi censurada, o que se traduz de que a perseguição da censura tinha como foco a lesbianidade não aceita pela sociedade.

O valor literário de Cassandra Rios atesta-se pela alta tiragem do público que a consumia, o sucesso das vendas de sua obra chegou a equiparar-se à tiragem de Jorge 1 D Amado, o qual a defendeu publicamente: "Cassandra Rios é mestre no ofício do D romance $(. .$.$) uma grande romancista ignorada por preconceito (...) O apagamento de$ Cassandra se dá devido o diálogo político de representação de grupos marginalizados" (MOTT, 1987, p. 118).

A censura que representa o destinatário de sua escritura tentou inúmeras vezes solapar a sua visibilidade, punindo-a e censurando mais de 36 títulos de sua obra. Cassandra foi a escritora mais perseguida na época da Ditadura Militar, entretanto, há menções de que até em farmácias vendiam-se clandestinamente exemplares de seus títulos.

Explicitamente, a autora assume a subliteratura que a crítica vigente da época a relega e é consciente da não legitimação dos objetos de sua escrita:

\begin{abstract}
Escrever sobre homossexualismo é uma incumbência delicada e perigosa: trabalho poucas vezes aceito, aprovado ou corretamente interpretado por aqueles que se interessam pelo assunto. Trazer a público trabalho desta envergadura não é tarefa fácil, nem sempre válida, quase suspeitosa, mesmo que contenha o mais elevado padrão cultural das obras assinadas por certos elementos respeitáveis nos anais da literatura (RIOS, 1972, p. 5).
\end{abstract}

Cassandra Rios sobreviveu um período hostil e soube canalizar sua ação mediante um terrível sistema estatal opressor e excludente, muitas vezes, utilizando-se de pseudônimos masculinos. Sua obra surpreende porque ela menciona a força motriz do desejo homoerótico feminino, em outras palavras, trata-se de uma mulher escrevendo sobre o tesão feminino em uma sociedade em que prevalecia o imaginário sociocultural cristão de que a mulher deveria ser submissa ao sexo com fins de reprodução e procriação da espécie humana em um ambiente privado, sem direitos de pulicizar ou emergir o seu desejo erótico.

Podemos enfatizar, portanto, que a escrita de Cassandra Rios emerge uma Literatura em que se valoriza e aproxima os sujeitos antes etéreos aos corpos e desejos, 
os textos dessa importante autora traz uma literatura em que é possível sentir na pele a dor e delicia de ser o que somos, paradoxalmente humanos.

\section{Considerações Finais}

Retomando ao início deste texto em que mencionei que se tratava de uma escrita intencional e não neutra que não enquadraria nos moldes de normas e técnicas de uma escrita acadêmica e como tratamos de literatura transgressiva, não canônica, desconhecida pela crítica, traço essas considerações finais com um poema de um esoritor conterrâneo da bicentenária cidade de Porto Nacional, estado do Tocantins, remanescente sobrevivente e resistente também da Ditadura Militar: Hamilton Pereira

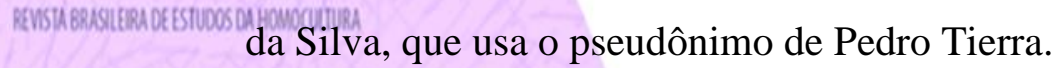

Ressalto, por fim, que este poema foi recitado em 2010, no Teatro Casa Grande, no Rio de Janeiro, no ato em apoio à candidatura de Dilma Rousseff: primeira mulher que ascendeu ao cargo mais importante da república federativa de nosso país e foi vítima de um golpe de estado que a depôs de seu cargo, eleita pelo voto direto de milhões de brasileiros.

Tal como a presidenta Dilma Rousseff, ouso metaforizar que Cassandra Rios também teve e continua tendo o seu direito literário usurpado mediante o silenciamento no currículo escolar e sua colocação à margem de uma literatura brasileira canônica.

Em ambos os casos, tratam-se de mulheres ousadas, "filhas da paixão" de uma geração que luta/lutou por um mundo mais equânime nas relações assimétricas de gênero e que buscaram romper os muros da privacidade, assumindo um protagonismo público e resistiram aos porões da tortura de Ditadura Militar brasileira que ainda predomina no âmago institucional de um país que insiste em silenciar a expressão da subjetividade feminina.

Afirmo, por fim, que a causa maior dessa tortura e tentativas de solapar direitos se deve ao fato da tentativa de visibilidade do gênero feminino em uma sociedade altamente misógina, machista, patriarcal, cisgênera, heteronormativa, falocêntrica e homolesbotransfóbica.

Eis o poema:

Os Filhos da paixão

Nascemos num campo de futebol

Haverá berço melhor para dar á luz uma estrela? 
Aprendemos que os donos do país só nos ouviam quando cessava o rumor da última máquina...

Quando cantava o arame cortado da última cerca...

Carregávamos no peito, cada um, batalhas incontáveis.

Somos a perigosa memória das lutas Projetamos a perigosa imagem do sonho

Nada causa mais horror à ordem do que homens e mulheres que sonham.

Nós sonhamos. E organizamos o sonho.

Nascemos negros, nordestinos, nisseis, índios, mulheres, mulatas, meninas de todas as cores, filhos, netos de italianos, alemães, árabes, judeus, portugueses, espanhóis, poloneses, tantos...

Nascemos assim desiguais, como todos os sonhos humanos.

Fomos batizados na pia, na água dos rios, nos terreiros

Fomos, ao nascer, condenados

a amar a diferença.

A amar os diferentes.

Viemos da margem.

Somos a anti-sinfonia

que estorna da estreita pautada melodia.

Não cabemos dentro da moldura...

Somos dilacerados como todos os filhos da paixão.

Briguentos. Desaforados. Unidos. Livres: como meninos de rua.

Quando o inimigo não fustiga,

inventamos nossas próprias guerras.

Desenvolvemos um talento prodigioso para elas...

Com nossas mãos, sonhos, desavenças,

compomos um rosto de peão,

uma voz rouca de peão,

o desassombro dos peões

para oferecer aos país,

para disputar o país.

Por sua boca dissemos, na fábrica, nos estádios, nas praças que este país não tem mais donos.

...A vida, não. A vida não falta.

E não há nada mais revolucionário que a vida.

Fixa suas próprias regras. Marca a hora

e se opõe diante de nós, incontornável

Os filhos da margem têm os olhos postos sobre nós.

Eles sabem, nós sabemos que a vida 


\section{não concederá uma terceira oportunidade.}

Hoje, temos uma cara. Uma voz. Bandeiras. Temos sonhos organizados.

Queremos um país onde não se matem as crianças

que escaparam do frio, da fome, da cola de sapateiro.

\section{Onde os filhos da margem tenham direito à terra, ao trabalho, ao pão, ao canto, à dança, às histórias que povoam nossa imaginação, às raízes da nossa alegria.}

\section{Aprendemos que a construção do Brasil não será obra apenas de nossas mãos. Nosso retrato futuro resultará da desencontrada multiplicação dos sonhos que desatamos.}

(Pedro Tierra, 1994).

\section{Referências}

ARAUJO, R. P. de. Estranhando o Currículo: a temática homoafetiva no ensino de Literatura Infantil. Rio de Janeiro: Metanoia, 2018.

BARROS, C. A. Iemanjá e pomba-gira: imagens do feminino na Umbanda. Dissertação de Mestrado do Programa de Pós-Graduação em Ciência da Religião. Juiz de Fora, 2006.

CANDIDO. A. O direito à Literatura. In: Vários escritos. $4^{\mathrm{a}}$ ed. São Paulo/Rio de Janeiro: Duas cidades/Ouro sobre azul, 2004.

CORRÊA, M. N. F.. Literatura, história e memória: uma leitura benjaminiana da poesia de Mario Benedetti. In: XII Congresso Internacional de Humanidades - Palavra e Cultura na América Latina, 2011, Brasília. Identidades em contato. Campinas: pontes editores, 2009.

DELCASTAGÈ, R. O espaço da dor. Editora Universidade de Brasília: Brasília, 1996.

FOUCAULT, M. História da Sexualidade: A Vontade de Saber. Rio de Janeiro: Graal, 1988.

MAINGUENEAU, D. O discurso pornográfico. São Paulo: Parábola Editorial, 2010.

MOTT, L. Lesbianismo no Brasil. Porto Alegre: Mercado Aberto, 1987. 
PERRONE-MOISÉS, L. Flores da Escrivaninha. São Paulo: Companhia das Letras, 1990.

RIOS, C. Muretta. Rio de Janeiro: Mundo Musical, 1972.

Censura. Minha luta, meu amor. São Paulo: Global Editora, 1977.

Maria Padilha. Rio de Janeiro: Record, 1980.

TIERRA, P. Os poemas do povo da noite. 3 ed. São Paulo: Editora Fundação Perseu Abramo, 2010. 